\title{
Research on Integrated Learning upon Enhancing Cognitive Activity in Primary School
}

\author{
Botakoz Zhekibayeva, ${ }^{1, \#, *}$, Assemgul Kalimova ${ }^{1, \#}$, Zhanar Sarsekeyeva $^{1, \#,}$ \\ Serafima Ossipova ${ }^{2, \#}$ and Gulpara Zhukenova ${ }^{3, \#}$ \\ ${ }^{1}$ Karaganda State University named after E.A. Buketov, Karaganda, Republic of Kazakhstan \\ ${ }^{2}$ Pavlodar State Pedagogical University, Pavlodar, Republic of Kazakhstan \\ ${ }^{3}$ L.N. Gumilyov Eurasian National University, Nur-Sultan, Republic of Kazakhstan
}

\begin{abstract}
Objective: The study aims to identify the possibility of using a set of methods that a future teacher can apply upon working with schoolchildren, and value-based attitudes, which subsequently develop the students' desire to learn.

Background: The model for preparing the teaching staff for work at school presupposes the presence of not only the already approved tools for assessing the quality of education but also the development of teaching principles. For this purpose, the structure of integrated education is applied, which forms the possibility of holistic comprehension of the surrounding world for schoolchildren and the use of technologies for sustainable education on the part of the teacher.

Method: To develop the above methods and attitudes, a pedagogical experiment was performed. In order to study the level of cognitive activity of young schoolchildren, experimental work based on the gymnasium was conducted.

Results: The authors demonstrate that integrated learning can be achieved only if the younger schoolchildren are prepared and discovered their individual way of thinking and desire for knowledge. The study identifies the possibility of using a set of methods that a future teacher can apply upon working with schoolchildren and value-based attitudes, which subsequently develop the students' desire to learn.

Conclusion: The authors have concluded that the use of the integrated learning methodology allows to expand pedagogical techniques and use them natively in high school.
\end{abstract}

Keywords: Professional education, learning processes, association, structure, training, development.

\section{INTRODUCTION}

The formation of national consciousness is absolutely important for every person, and for "special" children, too. It is extremely important for future teachers to understand the features of working with children with intellectual disabilities since such children have a different understanding of the world. The selfconsciousness of intellectual disability children is formed much later; it is distorted in comparison with their healthy peers. In general, the features of selfawareness and the possibility of its formation in intellectual disability children and adolescents are not well understood. It is necessary to study the peculiarities of the formation of national selfconsciousness since the problem of integrating children and adolescents with intellectual disabilities into society is currently an acute problem. In many respects, selfconsciousness determines personal development and features of regulation of behavior in society $[1,2]$.

It is necessary to develop and introduce new approaches in national education, adapting young

*Address correspondence to this author at the Karaganda State University named after E.A. Buketov, Karaganda, Republic of Kazakhstan; Tel: 87212356398; E-mail: b.zhekib4253@ust-hk.com.cn

\#These authors are equally contributed. people to new living conditions. According to N.N. Khan national education in the university can be represented as a managed socialization, purposeful activity, focused on creating conditions for the development of the intellectual potential of the student's personality, students' spirituality based on universal and national values, helping them in their life self-determination, moral, civil and professional development, ensuring self-realization legal security of an individual [3].

Formation of future teachers' national identity based on the integration of universal and national values contributes to the development of spiritual potential. A promising direction in the study of the problems of national self-awareness of a teacher is the formation of a high level of national self-consciousness as the teacher's dominant quality in his professional-pedagogical activity, the most important condition for his professionalism and competence [4,5]. The purpose of this study is to study the characteristics of the teacher's work with children with mental retardation and the theoretical justification of the national identity of such students in the context of a competency-based approach.

\section{LITERATURE REVIEW}

The study of culture and psychology has generated several influential theoretical perspectives $[6,7]$. Less 
attention, however, has been directed at the psychological basis of cultural experience. Culture is important not just because it teaches the skills needed to survive in a particular social and physical environment: It also satisfies a primary emotional need for security and predictability. A primitive attachment to culture goes beyond cognitive abilities and language to the very basis of human emotion and motivation. Thinking about cultural symbols in this way helps to understand the strength, and it can be argued, irrationality, of feelings and behaviors sometimes associated with them.

It has become clear that humans are endowed from birth with cognitive capacities that enable them to engage with and learn from others. From early infancy, children prefer human faces to other stimuli [8]; they show interest in the attentional objects of others [9]; and they are highly sensitive to others' emotional states [10]. From the earliest stages of their lives, normally developing humans actively engage with the social world, expressly seeking out and preferentially learning from interactions with other humans. These strong tendencies to seek out other people and to absorb social information are complemented by an, as far as we know, uniquely human degree of behavioral and cognitive flexibility. Human groups not only adapt their behaviors to different environments but also mold those environments in many ways to suit their needs. Cultures can be thought of as human-created "environmental niches" [11] held together by symbols and practices passed along across generations.

In the context of human development, these symbols and traditions become, over time, an integral part of how an individual comes to understand his own existence. As a child gradually learns to make sense of his existence in the world, his ideas about who he is and what purpose his life serves, are dependent upon his relationship to the symbols that hold society together.

Learning processes and learning biases explain much about social learning and cultural transmission, but they do not fundamentally explain the human motivation: They do not explain why humans actually do anything. If we, to some degree, accept arguments for modularity, or the relative isolation within the brain, of specific cognitive or information processing abilities [12], it is important to consider what drives humans to seek information in the first place. In other words, cognitive abilities and motivation should be thought of as complementary but separate domains. Something must drive humans to engage with the world and acquire the information they are so well equipped to process.

J. Panksepp's $[13,14]$ works in the field of affective neuroscience provide such a starting point: $\mathrm{He}$ has identified seven "primary process" emotional systems that have similar physiological substrates in all mammals: SEEKING, FEAR, PANIC, CARE, RAGE, LUST, and PLAY. Primary emotional systems motivationally shape engagement with the environment and thus serve to direct learning processes: A child will not explore its environment or actively seek out novel stimuli if it is experiencing fear or panic. From the earliest childhood, basic emotions provide the motivation for exploring and learning about the environment or retreating to the relative safety of the familiar. Through experience, the activation of particular emotional systems become associated with various stimuli - people, places, objects, etcetera, and a basic form of symbolism takes root.

As a child becomes more familiar with his environment, and his internal models of how the world works become more elaborate, the symbolic role of the caregiver as the primary source of security and safety is gradually supplanted by other developmentally relevant relationships and stimuli. Developmental psychologists $[15,16]$ point to clear shifts in the focus of children's attention as well as their conceptualization of the self as they progress from infancy through childhood and adolescence. Through a normal developmental process, the caregiver's emotional weight as the primary source of security, safety, and self-definition shifts to various peer groups [17] and later to more abstract symbols.

Through childhood and adolescence, there is a gradual expansion of symbolic safety zones related to greater knowledge of the world as well as an increased capability for abstraction. A meaningful sense of personal continuity develops [18, 19]. A sense of history and a sense of personal themes, capabilities, limitations, and likes and dislikes emerge. A symbolic sense of identity [20] develops.

However, the social nature of identity also relates to an intrinsic dark side, which is often overlooked [21]. When there are perceived threats to the social foundations of a person's identity; when people feel like their safety zones are somehow less secure; when unfamiliar practices and ideas knock at one's door, it is threatening. Threats to important social symbols are 
threats to the basic sense of the self: They threaten the sense of security and safety that is necessary to interact effectively with the world. Culture is the secure base from which enculturated individuals can explore comfortably.

\section{MATERIALS AND METHODS}

A desk review of the literature on competency frameworks was undertaken. A brief comparative analysis of the competencies frameworks was conducted to examine the similarities and differences between the frameworks. The experiment was carried out in stages based on the Abai Kazakh National Pedagogical University during the 2019 school year. For the experiment, control and experimental groups of students with approximately the same composition and initial level of knowledge of the majors were selected. There were 120 students in the experimental groups and 200 students in the control groups. In total, 320 students of 1-4 years of Abai Kazakh National Pedagogical University. The presented methodology has been implemented in the course of the procedure of group and individual surveys. The statistical processing of the data acquired was conducted with the use of software Microsoft Excel.

In order to identify the level of formation of the national self-consciousness of students, the first stage of the research was conducted: a survey on the study of associative connections of respondents in the field of the formation of national self-consciousness. The purpose of the questionnaire: the study of associative relationships with historical figures, literary works, traditions and customs, family relations, etc. Respondents not only chose but also submitted their own answers. The results of the questionnaire allowed to determine the influence of the territory of residence (city, village), knowledge of the native language, language of instruction to the level of formation of the national identity.

Competencies are skills that workers need to have in order to do their jobs well. A worker is judged competent when they have the ability to do a job properly. Core competencies are limited to those competencies that are commonly needed by workers to do a specific job, for example, to support people with disabilities living at home or in community-based settings. The purpose of a set of core competencies is to identify the operational skills required to do a job. Some competency frameworks include behavioural and personality traits (such as being flexible and adaptable), although these are often considered to be foundational skills that are job prerequisites and therefore deemed to be too general to be included in occupational specific competency frameworks. However, in the competencies for staff working with people with disabilities, it could be argued that these types of competencies that determine attitude are crucial.

A "competency framework" is a standardized structure that sets out and defines clearly each individual competency. These are usually in the form of skills statements that are specific observable actions that can be demonstrated by the worker. Table 1 outlines the difference between competencies and skill statements.

All procedures performed in studies involving human participants were in accordance with the ethical standards of the institutional and national research committee and with the 1964 Helsinki declaration and its later amendments or comparable ethical standards. A study was approved by the Central (National) Ethics

Table 1: Difference between a Competency and a Skilled Statement

\begin{tabular}{|c|c|c|}
\hline Competency Area & $\begin{array}{c}\text { A broad category within a competency framework containing } \\
\text { related information that describes knowledge skills or } \\
\text { abilities for effective work performance }\end{array}$ & Example \\
\hline \hline Competency description & $\begin{array}{c}\text { A statement describing themes of knowledge, skills or } \\
\text { abilities for effective work performance within a discrete } \\
\text { competency area }\end{array}$ & $\begin{array}{c}\text { The frontline staff member builds trust and } \\
\text { productive relationships with people s/he } \\
\text { supports, co-workers and others through } \\
\text { respectful and clear verbal and written } \\
\text { communication }\end{array}$ \\
\hline Skill statement & $\begin{array}{c}\text { A description of a competency standard that incorporates a } \\
\text { highly specific observable action (related to a competency } \\
\text { area) that may be demonstrated by the worker }\end{array}$ & $\begin{array}{c}\text { Communicates with the individual and his or her } \\
\text { family in a respectful and culturally appropriate } \\
\text { way }\end{array}$ \\
\hline
\end{tabular}

Source: Compiled by the authors. 
Commission of the Ministry of Health of the Republic of Kazakhstan, October 15, 2019, No 19A-36. Informed consent was obtained from all individual participants included in the study.

\section{RESULTS AND DISCUSSION}

\section{Features of the Teacher's Work with Children with Intellectual Disability}

Intellectual disability children are children who, as a result of organic brain lesions, experience a disturbance in the normal development of mental, especially higher cognitive processes (active perception, voluntary memory of verbal-logical thinking, speech, etc.). Mental retardation is not just a "small amount of the mind" it is a qualitative change in the whole psyche and personality as a whole, which is the result of transferred organic damage to the central nervous system. This is such an atypia of development that not only intellect suffers but also emotions, will, behavior, and physical development.

Studies by scientists have shown that children with intellectual disabilities have quite gross changes in conditioned reflex activity, imbalance in the processes of excitation and inhibition, and disturbances in the interaction of signal systems. All this is the physiological basis for the abnormal mental development of the child, including the processes of cognition, emotions, will, personality as a whole. Intellectual disability children are characterized by underdevelopment of cognitive interests, which is expressed in the fact that they are less than their peers and feel a need for knowledge [22, 23].

As research data shows, intellectual disability children at all stages of the cognition process have elements of underdevelopment, and in some cases, atypical development of mental functions. As a result, these children receive incomplete, and sometimes distorted ideas about the environment, their experience is extremely poor. It is known that with mental underdevelopment, the first stage of cognition, perception, is already defective. Often, the perception of intellectual disability children suffers due to a decrease in their hearing, vision, and speech underdevelopment, but also in those cases when the analyzers are preserved, the perception of these children differs in a number of features. The main disadvantage is a violation of the generalization of perception, and it's slowed pace is noted. Intellectual disability children require significantly more time to perceive the material they are offering (picture, text, etc.). The slowdown in perception is further aggravated by the fact that, due to mental underdevelopment, they hardly distinguish the main thing, do not understand the internal connections between parts, characters, etc. Therefore, their perception is also less differentiated. These learning features are manifested in a slower pace of recognition, as well as in the fact that students often confuse graphically similar letters, numbers, objects, similar sounds, words, etc.

A distinctive feature of the thinking of intellectual disability children is uncritical, the inability to independently evaluate their work. They often do not notice their mistakes. This is especially pronounced in mentally ill children, in children with damage to the frontal parts of the brain, and in imbeciles. They, as a rule, do not understand their failures and are satisfied with themselves, their work. All intellectual disability children are characterized by a decreased activity of thought processes and a weak regulatory role of thinking. Intellectual disability children often begin to do work without listening to the instructions, without understanding the purpose of the assignment, without an internal plan of action, with weak self-control [24].

Features of perception and comprehension by children of educational material are inextricably linked with the features of their memory. The main processes of memory - memorization, preservation, and reproduction - in intellectual disability children have specific features, as they are formed under conditions of abnormal development. They better remember external, sometimes random, visually perceptible signs. It is more difficult for them to recognize and remember internal logical connections. Intellectual disability later than their normal peers, voluntary memorization is formed, while the advantage of intentional memorization is not as pronounced as that of schoolchildren with normal intelligence. The weakness of the memory of the intellectual disability is manifested in the difficulties not so much in obtaining and maintaining information as in reproducing it, and this is their main difference from children with normal intelligence. Reproduction is a very complex process that requires a lot of volitional activity and focus. Due to a misunderstanding of the logic of events, the reproduction of the intellectual disability is unsystematic. Immaturity of perception, inability to use the techniques of memorization, and recalling leads intellectual disability children to errors in reproduction. The greatest difficulty is the reproduction of verbal material. Mediated semantic memory in intellectual disability children is poorly developed [25]. 
In order for children's education to proceed more successfully and be creative, a sufficiently developed imagination is necessary. In intellectual disability children, it is fragmented, inaccurate, and schematic. Since their life experience is poor, and mental operations are imperfect, the formation of imagination is unfavorable. An intellectual disability child more than his normal peers has expressed attention deficiencies: low stability, difficulty in distributing attention, slow switching. With oligophrenia, involuntary attention is greatly affected, but it is its arbitrary side that is predominantly underdeveloped. This is due to the fact that an intellectual disability child does not try to overcome them when difficulties arise. They, as a rule, in this case, quit work. However, if the work is interesting and feasible, it supports the attention of the child, without requiring much tension from them. The weakness of voluntary attention is also manifested in the fact that in the learning process, there is a frequent change in the objects of attention, the inability to concentrate on any one object, or one type of activity.

All these features of the mental processes of intellectual disability students affect the nature of the course of their activities. Noting the lack of education in the skills of educational activities, it should be noted first of all the underdevelopment of the focus of activities, as well as the difficulties of independent planning of one's own activity. Intellectual disability children begin work without the necessary prior orientation in it, are not guided by the ultimate goal. As a result, during the course of their work, they often move away from the correctly started execution of the action, slide off to the actions performed earlier, and transfer them unchanged, not considering that they are dealing with a different task. This departure from the goal is observed when difficulties arise, as well as in cases where the immediate motives for activity are leading ("just to do it"). Such children do not correlate the results obtained with the task that was set for them, and therefore cannot correctly evaluate its solution. Uncritically in their work is also a feature of the activities of these children [26, 27].

The underdevelopment of the cognitive, emotionalvolitional and personal spheres of students with mental retardation of different groups is manifested not only in qualitative and quantitative deviations from the norm, but also in the deep originality of their socialization. They are capable of development, although it is carried out slowly, atypically, and sometimes with sharp changes in the entire mental activity of the child. At the same time, despite the variety of individual variants of the structure of this violation, the prospects for the education of students with mental retardation are determined mainly by the severity of the underdevelopment of intelligence, while education, in any case, remains uncensored. Thus, modern scientific ideas about the features of the psychophysical development of different groups of students with mental retardation make it possible to highlight educational needs, both common to all students, and specific.

\section{Common needs include:}

- the allocation of the propaedeutic period in education, ensuring continuity between the preschool and school stages;

- the mandatory continuity of the correctional development process implemented both through the content of educational areas and in the process of individual work;

- early receipt of special assistance through education;

- psychological support that optimizes the interaction of the child with teachers and fellow practitioners;

- $\quad$ psychological support aimed at establishing the interaction of the family and the educational organization;

- the gradual expansion of the educational space that goes beyond the educational organization.

For students with mild mental retardation, the following specific educational needs are characteristic: increase the development time of the adapted educational program; the visual and effective nature of the content of education; simplification of the system of educational and cognitive tasks solved in the process of education; the inclusion in AOOP of educational activities that contribute to the formation of ideas about the world; development of communication tools, social skills; training to "transfer" the formed knowledge of skills into new situations of interaction with reality; the need for constant updating of knowledge, skills and community-approved norms of behavior; providing a special spatial and temporal organization of the educational environment, taking into account the functional state of the central nervous system and the neurodynamics of mental processes, students with mental retardation; the use of mainly positive means of stimulating activity and behavior; stimulation of 
cognitive activity, the formation of the need for cognition of the surrounding world and in interaction with it [28].

Based on the characteristics of the contingent, visiting compensatory groups, and the parents' request, the priority for the educational institution to implement the adapted general education program for preschool education is to create optimal conditions for the full correction and compensation of violations in the child's intellectual, speech and personal sphere. The maximum possible realization of the child's special educational needs, the maximum possible restoration of the rights of such a child to inherit social and cultural experience, express the goal and determine the value of rehabilitation by means of education.

\section{Analysis of the Formation of the National Identity of Future Teachers}

The focus of national education on the development of the national identity of the future teacher involves the pedagogical conditions, stages, and logic of the development of the system, methods, and technologies of national education, the conditions for the effective influence of the educational environment on the personality of the future teacher. The choice of methods was associated with the formation of the motivational - emotional, cognitive, and reflexivebehavioral components of the national identity of future teachers as professional competence.

The components of the national identity of future teachers as professional competence are formed when using technologies:

- pedagogical technologies aimed at the multicultural transformation of the student's personality: training for the development of cultural sensitivity, a reflection of ethno-cultural stereotypes, thematic and vitagenic workshopsdiscussions;

- technologies for modeling a multicultural environment: building universal values and creating unifying traditions, overcoming communication barriers, analytical conflict resolution;

- problem technologies, case technologies (analysis and resolution of situations) [29].

When analyzing the answers to the question, "What are the historical figures associated with below associated with?" Most of the respondents did not have difficulties with the associative links of the following names: Abu Nasr al-Farabi, Abai Kunanbayev, Alikhan Bokeykhanov, Ybyray Altynsarin, Shokan Valikhanov, Mukhtar Auezov. To the question: "What dishes belong to the traditional Kazakh cuisine?" $95 \%$ of respondents answered correctly. Answering the question: "What and to what extent, in your opinion, is it important to preserve Kazakhs living abroad?" Respondents noted the importance of preserving folk traditions and customs, using and respecting the native language. The greatest difficulty was the question of the content of proverbs and sayings. $39 \%$ of respondents feel a sense of pride in connection with their national identity. $28.5 \%$ of respondents show a positive ethnic identity, which indicates readiness for inter-ethnic interaction and communication, are interested in their own history and culture of other people. Answers to the questionnaire revealed:

- availability of knowledge in the field of history and culture, literature, knowledge of traditions and customs (the cognitive component of the national identity of future teachers);

- $\quad$ interest in the history, traditions, and culture of other nations (the motivational-emotional component of the national identity of future teachers);

- $\quad$ the ability to build a constructive dialogue with representatives of other cultures, the skill of intercultural communication, tolerant attitude to representatives of other ethnic communities (reflexively - the behavioral component of the national identity of future teachers). The results of the survey are presented in Table 2.

Table 2: The Level of Formation of the National Identity of Students

\begin{tabular}{|c|c|c|c|c|}
\hline \multirow{2}{*}{ Groups } & \multirow{2}{*}{$\begin{array}{c}\text { Number of } \\
\text { students }\end{array}$} & \multicolumn{3}{|c|}{ Levels } \\
\cline { 3 - 5 } & & Level of positive ethnic identity & Level of ethnic indifference & Hyperidality level \\
\hline \hline Experimental & 120 & $28 \%$ & $41 \%$ & $31 \%$ \\
\hline Control & 200 & $29 \%$ & $37.8 \%$ & $33.2 \%$ \\
\hline
\end{tabular}

Source: Compiled by the authors. 
An in-depth and comprehensive consideration of the formation of the national identity of future specialists is contained in the concept of "Mangilik El". Of particular interest is the content side of the concept, where the authors of the future specialist of the State of Kazakhstan consider the movement from ethnic (I) and civic identification (WE) to an intellectual and competitive nation to be the main vector of development of national self-awareness, national spirit, citizenship (ID). In the context of the most important components of the national idea, the competence approach, according to the authors, is aimed at the development and formation of future specialists:

- ethnic, ethnocultural, multicultural, inter-ethnic competences;

informational, communicative competences,
competencies related to the resolution of
problems;

- conflictological, socio-political, self-educational, research, and self-cognitive (reflective and identifying) competencies [30].

In training, the leading approach is the competence approach, which is firmly established in the university practice of many states of the world. This is due to many reasons. First, the competence-based approach, theory, and practice were a logical continuation of previous studies, which determined the basis for building the so-called future specialist model. Such a model was based on an analysis applied to the teacher, personal qualities of the future teacher, and, later, on the basis of the types of activities - design, research, methodological, educational, correctional, etc.

Secondly, the competence-based approach, implemented on the basis of identifying common, integrative competencies and private, specific areas of teacher training, specialty or specialization, made it possible to find imperative characteristics (criteria, parameters, measures, levels, etc.) that enable objective to assess the level of training of teachers in high school. Third, the opportunity has arisen to extrapolate the competence-based approach to the development of educational, scientific and methodological documentation, where within which sections and topics certain competencies should be formed - academic, subject, communicative, etc. The competency-based approach became not only the basis for designing new generation educational programs in higher school experience [31], but this process was especially accelerated due to the entry of the Republic of Kazakhstan into the Bologna process [32].

In our opinion, the integral component of the formation of the national identity of future teachers is the key competencies as a means of goal-setting and diagnosing the dynamics of the process of forming the national identity of future teachers. The analysis of theoretical literature allowed clarifying the concept of the phenomenon under study. In the context of the competence-based approach, national self-awareness is viewed by us as the competence of the teacher's personality, including several competencies that enable him to solve professional problems qualitatively in a holistic pedagogical process.

\section{The Formation of National Self-Awareness among Students with Mental Retardation: A Competency- Based Approach}

The widespread use of the term "competency" in pedagogical literature in recent years is due to the introduction of the competency-based approach to the educational space of many countries (including Russia), which is seen as an alternative to "knowledgeskills-skills" that limit the goals of teaching and upbringing to narrow subject education and insufficiently taking into account the essence of the competence of a modern person in free-market competition. In recent decades, in almost all developed countries of the European Union, in the context of the creation of a single educational space in the framework of the adopted Bologna Declaration, there has been a reorientation of the content of education towards the development of key competencies.

The competency-based approach reflects a type of educational content that does not come down to a knowledge-orientational component but includes a holistic experience in solving life problems, performing key functions, social roles, and manifesting competencies. A competency-based approach to education, as opposed to the concept of "learning", involves the development of students' skills that allow them to act effectively in the future in situations of professional, personal, and social life. Of course, subject knowledge does not disappear from the structure of education but plays a subordinate, orienting role in it [33].

The specifics of the professional activity of a teacher working with children with mental retardation 
should be manifested in the requirements for the subject of this work, i.e., in his professionally important qualities. Features of training and education of children with developmental disabilities imply increased requirements for professional competence, cognitive and personal characteristics of the teacher. These requirements include: knowledge of the specifics of the age and general mental development of intellectual disability children; knowledge of the specific behavior of intellectual disability children; special didactic abilities and skills aimed at overcoming the perceptual and mental limitations of intellectual disability children; knowledge, skills on the specifics of interpersonal perception and interpersonal relations of intellectual disability children.

Currently, the development of the national identity of the person, i.e., its civic competence, citizenship, patriotism, tolerance, active citizenship, interest in the history of its people, love for the motherland, respect for the laws of the state, a sense of responsibility for the fate of the country, internationalism, a set of moral and ethical values, a desire to participate in public life, is very important and a difficult stage in the formation of the whole society as a whole. When working with intellectual disability children, it is necessary to take into account the peculiarities of their development. Students with intellectual disabilities experience significant difficulties in mastering program material in core subjects. These difficulties are due to the developmental features of their higher mental functions. In this category of children, there is a significant lag in cognitive development. Today, the teacher is faced with the task of forming a national identity of the child's personality with mental retardation, emphasizing participation in public affairs, and the development of the rights and freedoms of a citizen of his country [34]. It is impossible to create national self-awareness in a child outside society; therefore, the task of each teacher is to familiarize their pupils with creative work, lay in them the need for creative self-realization, development within society, and teach them to be able to engage in political dialogue.

The education of national identity in intellectual disability children has a number of features associated with their mental and social-personal development. The result of the educational impact is much more difficult to achieve than their normally developing peers. But the intellectual disabilities that a child has should not change the general ideological orientation of educational work with him, which is of the same nature as in a mass school. However, it is necessary to take into account the peculiarities of the development of a child with intellectual disabilities, set feasible tasks for him, and use somewhat different forms and methods of work than children without intellectual disabilities.

The formation of national identity in children with intellectual disabilities is extremely difficult because they are characterized by violations in the development of higher mental functions, immaturity of the motivational sphere, weak motives for activity, and insufficient social needs. They are characterized by "close" motivation of activity, and the motivation of relations is primitive and elementary. Any motives are unstable, weakly expressed, and quickly disappear. National identification, citizenship, patriotism, spirituality, as the highest emotional qualities, are assimilated by children with mental retardation formally, do not pass into the category of their own motives.

Often the claims of adolescents with intellectual disabilities do not correspond to their real capabilities; the self-esteem of such students is inadequate. They cannot critically approach their judgments, actions, and deeds, hence the excessive overestimation or understatement of their moral qualities. Often the fundamental opinion is the opinion of an adult who enjoys authority among students. Therefore, it is important to correctly convey the basics of national self-awareness to the child without harming his perception of the world. The imagination of children with mental retardation is recreative, and since the development of several moral and psychological qualities of the person is associated with this mental process, only relying on a positive example can help build a sense of duty, humanity, responsibility, determination, responsiveness, and other positive personality qualities. In the absence of the necessary upbringing, such a child is easily amenable to someone else's negative influence and commits wrong, completely unlawful actions.

Higher spiritual feelings (conscience, sense of duty, responsibility, self-sacrifice, etc.) for intellectual disability students are formed with difficulty since their emergence is the process of combining feelings and thoughts. The underdevelopment of mental activity inhibits the formation of these feelings, and here the decisive role is played by the special educational system, which includes specific tasks. Its absence will lead to the spontaneous emergence of emotions and needs, which will replace higher feelings [35]. 
Summing up the above, it should be concluded that the collective nature of the activity is most effective in national and moral education matters. The efforts of each child in common work mutual assistance and interdependence are able to form the right attitude to each other. At the same time, teachers should help students with mental retardation develop their individual abilities and correct deficiencies, taking into account the peculiarities of their mental and emotionalpersonal development.

\section{CONCLUSIONS}

The competency-based approach to the formation of national identity in children with an intellectual disability is productive and promising because the position of the future teacher is based primarily on the idea of themselves as part of the Kazakh civilization, which has social and individual responsibility for this process. After all, the individual's moral behavior in the implementation of the ideas of a formed national identity consists of a combination of conscious actions of people or ethnic groups. The formed competences in the field of national identity formation in the educational process allow the future teacher to optimally act in restructuring the national education model, which will allow finding himself and his place in the great cultural diversity of the people of the Republic of Kazakhstan.

After analyzing the features of the teacher's work with children with intellectual disabilities in the context of the formation of their national identity, we made a number of conclusions. Children with intellectual disabilities have psychological characteristics that must be considered when building work, making it difficult to master generally accepted social norms. Teachers of an educational institution must have the necessary knowledge from the field of oligophrenopedagogy in order to correctly and efficiently organize work with children with intellectual disabilities, the work of raising national identity must be started from an early age in order to form the feelings inherent in a citizen and patriot of his country. National education of children with mental retardation is an urgent, but not sufficiently studied topic. It is difficult to find literature on the issues of national identification of this contingent in full. Networking with social partners for the national education of high school children with mental retardation, in our opinion, is a promising and innovative activity.

\section{ACKNOWLEDGEMENT}

None.

\section{REFERENCES}

[1] Khan NN. National education of student youth is a priority task for a modern university. Proceedings of KazUMOlmya named after Abylay Khan. Series Pedagogical Sciences 2013; 1: 42-45

[2] Sarbasova VN. National identity as a professionally significant quality teacher. Pedagogy and psychology in the modern world: theoretical and practical research. Moscow: Internauka Publishing House, 2017.

[3] Zhampeisova KK, Balykbayev TO, Khan NN, Kolumbayeva Sh. The content of the professional training of the teacher in Kazakhstan. Opcion 2018; 34(14): 683-710.

[4] Zhampeisova KK, Khan NN, Kolumbaeva ShZh. Professional standard of the teacher of the XXI century. Khabarshy Bulletin 2019; 1: 198-204

[5] Tarantey VP. Individual-typological approach in the educational and educational space of the educational institution. Grodno: Grodno State University, named after Yanka Kupala 2010.

[6] Henrich J, Heine SJ, Norenzayan A. The weirdest people in the world? Behavioral and Brain Sciences 2010; 33: 61-135. https://doi.org/10.1017/S0140525X0999152X

[7] Markus H, Kitayama S. Culture and selves: a cycle of mutual constitution. Perspectives on Psychological Science 2010; 5: 420-430.

https://doi.org/10.1177/1745691610375557

[8] Frank MC, Vul E, Johnson SP. Development of infants attention to faces during the first year. Cognition 2009; 110 : 160-170.

https://doi.org/10.1016/j.cognition.2008.11.010

[9] Hoehl S, Wiese L, Striano T. Young infants' neural processing of objects is affected by eye gaze direction and emotional expression. PLoS ONE 2008; 3: e2389. https://doi.org/10.1371/journal.pone.0002389

[10] Schore A. Affect regulation and the repair of the self. New York: Norton, 2003.

[11] Laland KN, Odling-Smee J, Feldman MW. Niche construction, biological evolution, and cultural change. Behavioral and Brain Sciences 2000; 23: 131-175. https://doi.org/10.1017/S0140525X00002417

[12] Sperber D, Hirschfeld LA. Culture and modularity. In: $P$ Carruthers, S. Laurence, S. Stich (Eds.), Culture and Cognition (pp. 149-164). New York: Oxford, 2007. https://doi.org/10.1093/acprof:oso/9780195310139.003.0010

[13] Panksepp J. Affective neuroscience: the foundations of human and animal emotions. Oxford: Oxford, 2004.

[14] Panksepp J. Cross-species affective neuroscience decoding of the primal affective experiences of humans and related animals. PLoS ONE 2011; 9: g001. https://doi.org/10.1371/journal.pone.0021236

[15] Erikson EH. Childhood and society. New York: Norton, 1950.

[16] Damon W, Hart D. Self-understanding in childhood and adolescence. New York: Cambridge University Press, 1988.

[17] Harris JR. The nurture assumption. New York: Touchstone 1998.

[18] Habermas T, Bluck S. Getting a life: the development of the life story in adolescence. Psychological Bulletin 2000; 126: 748-769. https://doi.org/10.1037/0033-2909.126.5.748

[19] McAdams DP. The psychology of life stories. Review of General Psychology 2001; 5: 100-122. https://doi.org/10.1037/1089-2680.5.2.100

[20] Erikson EH. Identity, youth and crisis. New York: Norton, 1968.

[21] Erikson EH. Life history and the historical moment. New York: Norton, 1975. 
[22] Shapoval IA. Special psychology. Moscow: TTS Sfera, 2005.

[23] Shipitsyna LM. "Uneducable" child in the family and society. Socialization of children with impaired intelligence. St Petersburg: Rech, 2005.

[24] Slepovich ES. Work with children with intellectual disability: the practice of special psychology. St Petersburg: Rech, 2008.

[25] Lubovsky VI, Rozanova TV, Solntseva LI. Special psychology. Moscow: ITS "Akademiya”, 2003.

[26] Chichevska-Jovanova N, Rashikj-Canevska O, KarovskaRistovska A, Dimitrova-Radojichikj D, Cekovska V. Specific learning difficulties manifestation in children with average inteligence and children with intellectual disabilities. Journal of Special Education and Rehabilitation 2018; 19(3-4): 7-24. https://doi.org/10.19057/jser.2019.37

[27] Morningstar ME, Kurth JA, Johnson PE. Examining national trends in educational placements for students with significant disabilities. Remedial and Special Education 2017; 38(1): 312. https://doi.org/10.1177/0741932516678327

[28] Crnic KA, Neece CL, Mclntyre LL, Blacher J, Baker BL. Intellectual disability and developmental risk: Promoting intervention to improve child and Family Well-Being. Child Development 2017; 88(2): 436-445. https://doi.org/10.1111/cdev.12740
[29] Oskolova TL. Formation of the national identity of students in a multicultural society. Tyumen: Russian State Vocational and Pedagogical University 2017.

[30] The concept of the implementation of the national idea of "Mangilik El" in the universities of Kazakhstan 2015. Retrieved from: http://kaznpu.kz/docs/novosti/ins_ped_psih/ conseption_mangilik_el_russian.pdf

[31] Pak YuN. Designing a new generation of educational programs: the experience of higher education in Kazakhstan. Almamater 2013; 9: 58-63.

[32] Pak YuN, Gazaliev AM. Bologna process and Kazakhstan realities. Karaganda: Publishing House of KSTU, 2012.

[33] Brunov BP. Parenting children with problems in intellectual development. Krasnoyarsk: Krasnoyarsk State Pedagogical University named after V.P. Astafiev, 2006.

[34] Butorina TS, Ovchinnikova NP. Education of patriotism by means of education. St. Petersburg: KARO, 2004.

[35] Wilmanskaya AD. The formation of the moral component of health in students of classes of correctional and educational learning by means of education. Education and Training of Children with Developmental Disorders 2008; 6: 10-11.

DOI: https://doi.org/10.6000/2292-2598.2020.08.03.16

(C) 2020 Zhekibayeva et al.; Licensee Lifescience Global.

This is an open access article licensed under the terms of the Creative Commons Attribution Non-Commercial License (http://creativecommons.org/licenses/by-nc/3.0/) which permits unrestricted, non-commercial use, distribution and reproduction in any medium, provided the work is properly cited. 